\title{
The flavonoids, quercetin and isorhamnetin 3-O-acylglucosides diminish neutrophil oxidative metabolism and lipid peroxidation
}

\author{
Małgorzata Zielińska $^{1 \bowtie}$, Artur Kostrzewa $^{2}$, Ewa Ignatowicz ${ }^{1}$ and \\ Jaromir Budzianowski ${ }^{3}$ \\ ${ }^{1}$ Department of Pharmaceutical Biochemistry, ${ }^{2}$ Department of Immunodiagnostics, \\ and ${ }^{3}$ Department of Pharmaceutical Botany, Karol Marcinkowski University of Medical \\ Sciences, Poznań, Poland
}

Received: 20 September, 2000; revised: 8 January, 2001; accepted: 13 February, 2001

Key words: flavonoids, respiratory burst, reactive oxygen species, flow cytometry, lipid peroxidation, polymorphonuclear neutrophils

\begin{abstract}
Two natural flavonoids, quercetin and isorhamnetin 3-O-acylglucosides, were examined for their inhibitory influence on the in vitro production and release of reactive oxygen species in polymorphonuclear neutrophils (PMNs). The generation of superoxide radical, hydrogen peroxide and hypochlorous acid were measured by, respectively, cytochrome $c$ reduction, dichlorofluorescin oxidation and taurine chlorination. Membrane lipid oxidation was studied by the thiobarbituric acid method in mouse spleen microsomes. The addition of flavonoids at the concentration range 1-100 $\mu \mathrm{M}$ inhibited PMNs oxidative metabolism and lipid peroxidation in a dose-dependent manner. The results suggest that these flavonoids suppress the oxidative burst of PMNs and protect membranes against lipid peroxidation.
\end{abstract}

The most dangerous agents released during inflammation comprise, among others, reactive oxygen species (ROS), produced in great amounts by polymorphonuclear neutrophils (PMNs). Stimulation of these cells leads not only to phagocytosis and release of lysosomal enzymes and arachidonic acid metabolites, but also to superoxide radical $\left(\mathrm{O}_{2}^{\bar{\alpha}}\right)$ generation. Superoxide radical is metabolised to hydrogen peroxide $\left(\mathrm{H}_{2} \mathrm{O}_{2}\right)$ by super- oxide dismutase (SOD) and the resulting peroxide is further converted to hypochlorite $\left(\mathrm{OCl}^{-}\right)$by azide-sensitive myeloperoxidase (MPO). Hydrogen peroxide, superoxide radical and hypochlorous acid exhibit direct antimicrobial activity, but also damage host tissues and oxidize physiological substrates of crucial biological significance (membrane lipids, nucleic acids and proteins) [1].

\footnotetext{
${ }^{\otimes}$ Małgorzata Zielińska, Department of Pharmaceutical Biochemistry, Karol Marcinkowski University of Medical Sciences, Grunwaldzka 6, 60-780 Poznań, Poland; tel: (48 61) 865 9605; fax: (48 61) 865 9566; e-mail: mzielin@mail.usoms.poznan.pl

Abbreviations: BHA, butylated hydroxyanisole; DCFH, dichlorofluorescin; DCFH-DA, 2' , 7'-dichlorofluorescin diacetate; MDA, malondialdehyde; MPO, myeloperoxidase; $\mathrm{NaCl} / \mathrm{P}_{\mathrm{i}}$, phosphate-buffered saline; PMA, phorbol myristate acetate; PMNs, polymorphonuclear neutrophils; ROS, reactive oxygen species; SOD, superoxide dismutase.
} 
Reactive oxygen species are involved in numerous pathological events, including inflammation, radiation damage, metabolic disorders, cellular aging, reperfusion damage, atherosclerosis and carcinogenesis. Evidence for a potential role of oxidants in the pathogenesis of many diseases suggests that antioxidants may be of therapeutic use in these conditions [2-4].

Many natural flavonoids show anti-inflammatory properties, based on several mechanisms including the effect on free radical formation or radical scavenging [4-7].

In the present study we assessed the antioxidant effect of two flavonoids: isorhamnetin 3-O- $\left(6^{\prime \prime}-O\right.$ acetyl)glucoside isolated from Solidago canadensis var. scabra and quercetin 3-O-(6' '-O-galloyl)glucoside from Drosera aliciae Hamet on human PMNs and mouse spleen microsomes. The flavonoid activity was compared to the effects of quercetin and butylated hydroxyanisole, a standard antioxidant and a food preservative, respectively.

\section{MATERIALS AND METHODS}

Flavonoids. Isorhamnetin 3-O-(6'-O-acetyl) glucoside was isolated and identified from goldenrod flowers, Solidago canadensis var. scabra (Asteraceae) [8]. Quercetin 3-O-(6' '-O-galloyl)glucoside was isolated and identified from sundew shoots, Drosera aliciae Hamet (Droseraceae), obtained from the in vitro culture. These compounds were of high purity as judged by their ${ }^{1} \mathrm{H}$ - and ${ }^{13} \mathrm{C}$ NMR spectra, which showed no signals of impurities [8]. Flavonoids were tested in the concentration range $1-100 \mu \mathrm{M}$. The activity of the examined flavonoids was compared to the activity exerted by quercetin and butylated hydroxyanisole, in the same range of concentrations.

Reagents. 2',7'-dichlorofluorescin diacetate (DCFH-DA) was purchased from Acros Organics (New Jersey, U.S.A.). Butylated hydroxyanisole (BHA), ferricytochrome $c$, phorbol myristate acetate (PMA), quercetin, superoxide dismutase (SOD), taurine and zymosan-A were from Sigma Chemical Co. (St. Louis, MO, U.S.A.). Butylated hydroxyanisole was dissolved in dimethyl sulfoxide and then diluted in phosphate-buffered saline $\left(\mathrm{NaCl} / \mathrm{P}_{\mathrm{i}}\right.$, Biomed, Lublin, Poland). Zymosan-A was opsonized for $30 \mathrm{~min}$ at $37^{\circ} \mathrm{C}$ in normal human serum (10 $\mathrm{mg} / \mathrm{ml}$, AB group), washed twice with $\mathrm{NaCl} / \mathrm{P}_{\mathrm{i}}$ and stored at $-20^{\circ} \mathrm{C}$ until use [9].

Preparation of PMNs. Peripheral venous blood from healthy adult volunteers was collected in heparinized tubes (10 U/ml blood). Neutrophils were isolated by Gradisol $\mathrm{G}(\mathrm{d}=1.115 \mathrm{~g} / \mathrm{ml}$; "AquaMedica" s.c., Poland) density gradient centrifugation [10]. Viability was checked by trypan blue exclusion.

Preparation of microsomes. Microsomes were prepared according to the previously described method [11]. Briefly, female Swiss mice (7-9 week old, $25 \mathrm{~g}$ ) were sacrificed by cervical dislocation and their spleens were removed and homogenized in 0.25 $\mathrm{M}$ sucrose/0.05 M Tris, 0.025 M $\mathrm{KCl}, 0.003 \mathrm{M} \mathrm{MgCl} 2$ buffer (pH, 7.55). Five spleens were weighed and pooled to form each experimental group. Two volumes of the above buffer were taken for one volume of tissue. Microsomal fractions were obtained by centrifuging the whole homogenate at $10000 \times \boldsymbol{g}$ for $30 \mathrm{~min}$ and then centrifuging the supernatant at $100000 \times \boldsymbol{g}$ for $60 \mathrm{~min}$. Microsomal pellets were suspended in $0.01 \mathrm{M}$ phosphate buffer ( $\mathrm{pH}, 7.4$ ) containing $20 \%$ (v/v) glycerol. Protein concentration was determined by the method of Lowry et al. [12].

Measurement of $\mathrm{O}_{2}$ formation. The rate of superoxide anion production was measured by reduction of ferricytochrome $c$, according to Cohen $\&$ Chovaniec [13]. A reaction mixture $(0.5 \mathrm{ml}$ total volume) of $1 \times 10^{6} \mathrm{PMNs}$ stimulated by opsonized zymosan (1 $\mathrm{mg} / \mathrm{ml}$ ), was incubated for 20 min at $37^{\circ} \mathrm{C}$ with $0.6 \mathrm{mg}$ of ferricytochrome $c$ in $\mathrm{NaCl} / \mathrm{P}_{\mathrm{i}}$. Absorbance of cell-free supernatants was measured at $550 \mathrm{~nm}$ following the addition of $310 \mathrm{U}$ of SOD. The absorbance was converted to nanomoles of $\mathrm{O}_{2}^{\bar{*}}$ using the absorption coefficient $\mathrm{A}_{550}=21.1 \mathrm{mM}^{-1} \times \mathrm{cm}^{-1}$ [14].

Taurine chlorination assay. The amount of $\mathrm{HOCl}$ was measured by chlorination of taurine, according to Weiss et al. [15]. PMNs $\left(1 \times 10^{6}\right)$ stimulated by opsonized zymosan (1 $\mathrm{mg} / \mathrm{ml}$ ), were incubated for $60 \mathrm{~min}$ at $37^{\circ} \mathrm{C}$ with $15 \mathrm{mM}$ taurine in $\mathrm{NaCl} / \mathrm{P}_{\mathrm{i}}, \mathrm{pH}$, 7.4. Absorbance of 
cell-free supernatants was determined at $350 \mathrm{~nm}$ following the addition of $20 \mathrm{mM} \mathrm{KJ}$. The absorbance was directly proportional to the amount of $\mathrm{HOCl}$ (absorption coefficient $\mathrm{A}_{350}=$ $22.9 \mathrm{mM}^{-1} \times \mathrm{cm}^{-1}$ ).

Flow cytometric assay of dichlorofluorescin (DCFH) oxidation. The intracellular production of ROS in stimulated neutrophils was quantified in individual cells by flow cytometry using the procedures described by Bass et al. [16]. Fifty milliliters of heparinized whole blood was incubated with $15 \mu \mathrm{l}$ of $0.3 \mathrm{mM} \mathrm{2} 2^{\prime}, 7^{\prime}$-dichlorofluorescin diacetate (DCFH-DA) in $\mathrm{NaCl} / \mathrm{P}_{\mathrm{i}}$ for $30 \mathrm{~min}$. After that phorbol myristate acetate (PMA, $10 \mu \mathrm{g} / \mathrm{ml}$ ) as neutrophil-stimulating agent was added. The erythrocytes were removed by $1 \mathrm{ml}$ of the Ortho-mune lysing reagent. Intracellular DCF fluorescence of PMNs was determined by flow cytometry (Cytoron Absolute, Ortho, U.S.A.) at $488 \mathrm{~nm}$ excitation wavelength. DCF fluorescence was measured with a green filter $(515-548 \mathrm{~nm})$ in the linear range of signal amplification [17]. Fluorescence intensity was expressed as the value of the "mean channel", calculated by the ImmunoCount 2 software (Ortho). All assays were performed after 30 min incubation of PMNs with flavonoids in the concentration range from 1 to $100 \mu \mathrm{M}$. Control samples contained $\mathrm{NaCl} / \mathrm{P}_{\mathrm{i}}$ only.

Lipid peroxidation. The complete incubation mixture consisted of a suspension of mouse spleen microsomes in $1.5 \mathrm{ml}$ of $0.15 \mathrm{M}$ Tris $/ \mathrm{HCl}$, $1 \mathrm{mM} \mathrm{KH}_{2} \mathrm{PO}_{4}$ buffer, $\mathrm{pH} 7.4$, at a final concentration of $1 \mathrm{mg}$ protein and various concentrations of the tested compounds, and additionally $0.01 \mathrm{mM} \mathrm{FeSO}_{4}$ and $0.05 \mathrm{mM} \mathrm{L(+)-ascorbic} \mathrm{acid}$ (non-enzymatic lipid peroxidation). The level of malondialdehyde (MDA)-like substances used as an index of lipid peroxidation was assayed with the 2-thiobarbituric acid (TBA) using molar absorption coefficient of $1.56 \times 10^{5} \mathrm{M}^{-1} \times \mathrm{cm}^{-1} \lambda$. Results were expressed as $\mu$ mols of MDA equivalents/mg protein [18].

Statistical analysis. Values are means \pm S.E. The differences between the means of treatment groups and appropriate controls were assessed with the paired two-tailed $t$-test. Differences were considered to be significant if $P<0.05$. The results are presented in appropriate concentration units per $1 \times 10^{6}$ cells and as the percentage of remaining metabolic activity as compared to controls $(100 \%)$.

\section{RESULTS AND DISCUSSION}

Flavonoids are natural components of human and animal diet and have been shown to exert different biological effects, such as antiviral, anti-inflammatory, antimutagenic and anticarcinogenic functions. This activity is reported to result partly from their antioxidant and antiradical properties $[19,20]$. The results presented below corroborate the previous finding that some flavonoids suppress the oxidative metabolism in polymorphonuclear neutrophils [17].

The three flavonols tested (structures depicted in Fig. 1), as well as BHA, significantly diminished the amount of ROS generated in stimulated PMNs with the exception of isorhamnetin acetylglucoside, which showed no inhibition of hypochlorous acid production (Table 1, 2, 3). The inhibitory effect appeared to be concentration-dependent and was most pronounced at $100 \mu \mathrm{M}$, except for the influence of isorhamnetin acetylglucoside on superoxide radical (Table 1) and hypochlorous acid production (Table 1, 2). Quercetin galloylglucoside exhibited pronounced activity comparable to that of quercetin (Table 1, 2,3 ), but the latter was much stronger as an inhibitor of lipid peroxidation (Table 4). These compounds were stronger than BHA only as inhibitors of superoxide radical production (Table 2). In turn, isorhamnetin acetyl glucoside appeared to be the weakest antioxidant among the flavonoids tested in respect to each ROS measured.

Tauber et al. [21] investigated the inhibition of NADH-dependent oxidase by flavonoids in polymorphonuclear neutrophiles. Some of the compounds tested, including quercetin, were active inhibitors either in intact or in disrupted cells, whereas others acted in disrupted PMNs only. The authors concluded that flavonoid passage through the cell membrane and its ability to interfere with respiratory burst depends on the number and position of free hydroxyl groups in the flavonoid core structure. The decisive roles 
are played by the hydroxyl group situated at the $\mathrm{C} 3$ position in the $\mathrm{C}$ ring with the adjacent $\mathrm{C} 2-\mathrm{C} 3$ double bond. Another feature important for the as monophenolic rings are weaker hydrogen donors. The similar activity of quercetin galloylglucoside and quercetin itself may be explained as

\begin{tabular}{llllll}
\hline Compound & $\mathrm{R}_{1}$ & $\mathrm{R}_{2}$ & $\mathrm{R}_{3}$ & $\mathrm{R}_{4}$ & $\mathrm{R}_{5}$ \\
\hline Quercetin & $\mathrm{OH}$ & $\mathrm{OH}$ & $\mathrm{H}$ & $\mathrm{OH}$ & $\mathrm{OH}$ \\
Quercetin-3-O-(6"'-O-galloyl)glucoside & $\mathrm{OH}$ & $\mathrm{OH}$ & glucose-6"'-galloyl & $\mathrm{OH}$ & $\mathrm{OH}$ \\
Isorhamnetin-3-O-(6"'-O-acetyl)glucoside & $\mathrm{OH}$ & $\mathrm{OH}$ & glucose-6"'-acetyl & $\mathrm{OCH}_{3}$ & $\mathrm{OH}$ \\
\hline
\end{tabular}<smiles>[R6]OC1=C(c2ccc([R6])c([R2])c2)Oc2cc([R])cc([R])c2C1O</smiles>

Figure 1. Chemical structure of the examined flavonoid derivatives.

antioxidative power is the ortho arrangement of the two hydroxyl groups (free catechol grouping) in the B ring of the flavonoid core [22]. However, naturally occurring flavonoids are usually O-glycosides with sugar moieties bound mostly at follows. The activity-lowering effect of glucosidation at $\mathrm{C} 3$ of the aglycon is cancelled out by the presence of the galloyl group known for its antioxidative properties [22]. In vitro experiments cannot be easily related to the in vivo pharmaco-

Table 1. Effect of quercetin and isorhamnetin acylglucosides, quercetin and BHA on superoxide radical generation by human PMNs ${ }^{a, b}$. Values represent nmol $\mathrm{O}_{2}^{\overline{2}} / 1 \times 10^{6} \mathrm{PMNs}$.

\begin{tabular}{|c|c|c|c|c|}
\hline Compound & Control & $1 \mu \mathrm{M}$ & $10 \mu \mathrm{M}$ & $100 \mu \mathrm{M}$ \\
\hline \multirow[t]{2}{*}{ Isorhamnetin-3-O-(6" $-O$-acetyl)glucoside } & $8.4 \pm 0.5$ & $\begin{array}{c}6.4 \pm 0.5 \\
* *\end{array}$ & $\begin{array}{c}6.0 \pm 0.4 \\
* *\end{array}$ & $\begin{array}{c}6.3 \pm 0.3 \\
*\end{array}$ \\
\hline & $100 \%$ & $76.5 \%$ & $72.1 \%$ & $75.5 \%$ \\
\hline \multirow[t]{2}{*}{ Quercetin-3-O-(6"'-O-galloyl)glucoside } & $8.7 \pm 0.7$ & $\begin{array}{c}6.7 \pm 0.6 \\
*\end{array}$ & $\begin{array}{c}5.8 \pm 0.5 \\
* *\end{array}$ & $\begin{array}{c}0.8 \pm 0.2 \\
* * *\end{array}$ \\
\hline & $100 \%$ & $77.1 \%$ & $66.9 \%$ & $9.0 \%$ \\
\hline \multirow[t]{2}{*}{ Quercetin } & $8.7 \pm 0.7$ & $\begin{array}{c}5.9 \pm 0.4 \\
* *\end{array}$ & $\begin{array}{c}5.7 \pm 0.5 \\
* *\end{array}$ & $\begin{array}{c}0.8 \pm 0.2 \\
* * *\end{array}$ \\
\hline & $100 \%$ & $67.6 \%$ & $65.3 \%$ & $9.3 \%$ \\
\hline \multirow[t]{2}{*}{ BHA } & $8.5 \pm 0.5$ & $8.6 \pm 0.8$ & $8.3 \pm 0.5$ & $6.8 \pm 0.8$ \\
\hline & $100 \%$ & $101.3 \%$ & $97.5 \%$ & $79.8 \%$ \\
\hline
\end{tabular}

${ }^{\mathrm{a}}$ Values are means \pm S.E. of 11 experiments. ${ }^{\mathrm{b}}$ Significantly different from the untreated control: $* P<0.05 ; * * P<0.01$; $* * * P<0.001$.

the C3 position, hence are weaker antioxidants than their aglycons [6, 22]. Isorhamnetin is deprived of free catechol function due to the substitution of the C3' hydroxyl group with a methyl group. Hence, it is less efficient as an antioxidant kinetics of ingested dietary polyphenols as the kind of sugar moiety determines the rate of flavonoid glycoside absorption from the small gut, and its bioavailability [2]. Havsteen has suggested cleavage of the sugar moieties by glycosidases 
Table 2. Effect of quercetin and isorhamnetin acylglucosides, quercetin and BHA on hypochlorous acid production by human PMNs ${ }^{\text {a,b }}$. Values represent nmol HOCl/1 $\times 10^{6} \mathrm{PMNs}$.

\begin{tabular}{|c|c|c|c|c|}
\hline Compound & Control & $1 \mu \mathrm{M}$ & $10 \mu \mathrm{M}$ & $100 \mu \mathrm{M}$ \\
\hline \multirow[t]{2}{*}{ Isorhamnetin-3-O-(6"'-O-acetyl)glucoside } & $93.6 \pm 5.5$ & $96.3 \pm 6.6$ & $93.8 \pm 6.5$ & $101.0 \pm 2.14$ \\
\hline & $100 \%$ & $102.9 \%$ & $100.2 \%$ & $107.9 \%$ \\
\hline \multirow[t]{2}{*}{ Quercetin-3-O-(6"'-O-galloyl)glucoside } & $111.0 \pm 3.6$ & $109.9 \pm 2.6$ & $\begin{array}{c}90.7 \pm 2.6 \\
* * *\end{array}$ & $\begin{array}{c}37.5 \pm 2.7 \\
* * *\end{array}$ \\
\hline & $100 \%$ & $99.0 \%$ & $81.8 \%$ & $33.5 \%$ \\
\hline \multirow[t]{2}{*}{ Quercetin } & $111.0 \pm 3.6$ & $107.7 \pm 3.0$ & $\begin{array}{c}90.3 \pm 3.8 \\
* * *\end{array}$ & $\begin{array}{c}37.7 \pm 3.3 \\
* * *\end{array}$ \\
\hline & $100 \%$ & $97.0 \%$ & $81.4 \%$ & $33.9 \%$ \\
\hline \multirow[t]{2}{*}{ BHA } & $89.9 \pm 6.3$ & $\begin{array}{c}68.9 \pm 4.5 \\
* * *\end{array}$ & $\begin{array}{c}25.4 \pm 2.1 \\
* * *\end{array}$ & $\begin{array}{c}24.5 \pm 2.3 \\
* * *\end{array}$ \\
\hline & $100 \%$ & $76.6 \%$ & $28.2 \%$ & $27.3 \%$ \\
\hline
\end{tabular}

${ }^{\mathrm{a}}$ Values are means \pm S.E. of 11 experiments. ${ }^{\mathrm{b}}$ Significantly different from the untreated control: ${ }^{* * *} P<0.001$.

from intestinal bacteria and aglycon uptake in enterocytes [19]. Recent data present evidence on the transportation of the major dietary flavonoid, quercetin- 4 '- $\beta$-glucoside, across the apical membrane of enterocytes. The mechanism of this transport is complex and involves intestinal sodium-dependent D-glucose transporter [23]. Additionally, quercetin- $4^{\prime}-\beta$-glucoside is effluxed by multidrug resistance-associated protein [24]. However, the transport kinetics in intestine cells does not reflect the absorption of flavonoids in other cells.

The suggested mechanism of the antioxidative activity of flavonoids involves the suppression of radical generating enzymes and free radicals scavenging, regardless of their enzymatic or nonenzymatic provenience [21, 25-27]. Another postulated mechanism of flavonoid antioxidant activity is transition metal chelation. This preventive function interferes with the conversion of hydrogen peroxide into hydroxyl radical (Haber-Weiss reaction) [28]. Hydroxyl radical is chiefly responsible for lipid peroxidation, which impairs the normal function of cell membranes: motility and permeability. It has been suggested that metal ion chelation by flavonoids prevents lipid peroxidation by restricting the access of the metal ions toward fatty acids in phospholipids either in natu-

Table 3. Effect of quercetin and isorhamnetin acylglucosides, quercetin and BHA on hydrogen peroxide production by human PMNs ${ }^{\text {a,b }}$. Values represent "mean channel”.

\begin{tabular}{|c|c|c|c|c|}
\hline Compound & Control & $1 \mu \mathrm{M}$ & $10 \mu \mathrm{M}$ & $100 \mu \mathrm{M}$ \\
\hline \multirow[t]{2}{*}{ Isorhamnetin-3-O-(6"'-O-acetyl)glucoside } & $123.6 \pm 7.1$ & $118.1 \pm 6.7$ & $\begin{array}{c}111.9 \pm 9.3 \\
*\end{array}$ & $\begin{array}{c}107.7 \pm 8.1 \\
*\end{array}$ \\
\hline & $100 \%$ & $95.6 \%$ & $90.5 \%$ & $87.2 \%$ \\
\hline \multirow[t]{2}{*}{ Quercetin-3-O-(6' '-O-galloyl)glucoside } & $121.4 \pm 6.6$ & $118.5 \pm 6.7$ & $113.1 \pm 8.2$ & $\begin{array}{c}97.7 \pm 6.1 \\
*\end{array}$ \\
\hline & $100 \%$ & $97.6 \%$ & $93.2 \%$ & $80.5 \%$ \\
\hline \multirow[t]{2}{*}{ Quercetin } & $121.4 \pm 6.6$ & $120.8 \pm 7.5$ & $111.2 \pm 7.3$ & $\begin{array}{c}100.5 \pm 7.7 \\
*\end{array}$ \\
\hline & $100 \%$ & $99.5 \%$ & $91.6 \%$ & $82.8 \%$ \\
\hline \multirow[t]{2}{*}{ BHA } & $123.6 \pm 7.1$ & $120.7 \pm 7.8$ & $120.9 \pm 8.0$ & $\begin{array}{c}103.4 \pm 8.5 \\
* *\end{array}$ \\
\hline & $100 \%$ & $97.7 \%$ & $97.8 \%$ & $83.7 \%$ \\
\hline
\end{tabular}

${ }^{\mathrm{a}}$ Values are means \pm S.E. of 7 experiments. ${ }^{\mathrm{b}}$ Significantly different from the untreated control: ${ }^{*} P<0.05 ;{ }^{* *} P<0.01$ 
Table 4. Effect of quercetin and isorhamnetin acylglucoside, and quercetin on non-enzymatic lipid peroxidation in mouse spleen microsomes ${ }^{\text {a,b }}$. Results expressed as pmoles of MDA equivalents/mg protein

\begin{tabular}{lcccc}
\hline Compound & Control & $1 \mu \mathrm{M}$ & $10 \mu \mathrm{M}$ & $100 \mu \mathrm{M}$ \\
\hline Isorhamnetin-3-O-(6"'-O-acetyl)glucoside & $41.0 \pm 8.3$ & $39.2 \pm 5.0$ & $37.4 \pm 6.1$ & $30.1 \pm 4.1$ \\
& $100 \%$ & $95.6 \%$ & $91.2 \%$ & $73.4 \%$ \\
Quercetin-3-O-(6"'-O-galloyl)glucoside & $41.0 \pm 8.3$ & $36.5 \pm 6.0$ & $35.2 \pm 6.6$ & $\begin{array}{c}21.0 \pm 8.5 \\
* *\end{array}$ \\
& $100 \%$ & $89.0 \%$ & $85.9 \%$ & $51.2 \%$ \\
Quercetin & $41.0 \pm 8.3$ & $31.8 \pm 3.9$ & $30.2 \pm 6.1$ & $7.7 \pm 3.8$ \\
& $100 \%$ & $77.6 \%$ & $73.4 \%$ & $18.9 \%$ \\
\hline
\end{tabular}

${ }^{\mathrm{a}}$ Values are means \pm S.E. of 7 experiments. ${ }^{\mathrm{b}}$ Significantly different from the untreated control: ${ }^{*} P<0.05 ;{ }^{* *} P<0.01$; ${ }^{* * *} P<0.001$

ral or in synthetic membranes. However, some flavonols can inhibit lipid peroxidation at a concentration too low to chelate efficiently the supplemented metal ions. Therefore, an additional antioxidant mechanism should be postulated for flavonoids, namely termination of the chain reaction of lipid peroxidation [20]. Our data show that non-enzymatic lipid peroxidation was reduced in PMNs treated with flavonoids.

The observed discrepancy between isorhamnetin $3-O-\left(6^{\prime \prime}-O\right.$-acetyl $)$ glucoside activity towards hydrogen peroxide generation, measured directly as DCFH-DA oxidation and indirectly as phenol red oxidation, may be caused by the basic methodological differences. In the method used in our study, the probe, 2',7'-dichlorofluorescin diacetate, fluoresces directly upon intracellular hydrolysis and oxidation. With the use of the same fluorescent probe, quercetin has been found to reduce intracellular hydrogen peroxide accumulation [4].

The other assays presented in our study measure indirectly the extracellular release of respiratory burst products and their diminishment upon flavonoid treatment.

The data presented above show the antioxidant potency of plant-derived flavonoids, which may contribute to biological effect of herbal drugs and dietary fruit and vegetable. Flavonoids have been investigated for their use as natural food preservatives as well as for their health-promoting properties in humans [2]. Flavonoids are members of larger chemical group, polyphenols, which have known preventive activities against degenerative diseases, e.g. coronary heart disease or some types of cancer [2, 25].

The present data propose that flavonoids like quercetin or isorhamnetin derivatives may be effective protectors of cells against oxidative stress and free radical-induced toxicity.

\section{R E F E R E N C E S}

1. Edwards, S.W. (1994) The respiratory burst: The generation of reactive oxygen metabolites and their role in microbial killing; in: Biochemistry and Physiology of Neutrophil; pp. 149-179, Cambridge University Press, Cambridge.

2. Hollman, P.C.H. \& Katan, M.B. (1999) Dietary flavonoids: Intake, health effects and bioavailability. Food Chem. Toxicol. 37, 937-942.

3. Halliwell, B. (1996) Oxidative stress, nutrition and health. Experimental strategies for optimization of nutritional antioxidant intake in humans. Free Radical Res. 25, 57-74.

4. Skaper, S.D., Fabris, M., Ferrari, V., Carbonare, M.D. \& Leon, A. (1997) Quercetin protects cutaneous tissue-associated cell types including sensory neurons from oxidative stress induced by glutathione depletion: Cooperative effects of ascorbic acid. Free Radic. Biol. Med. 22, 669-678.

5. Catapano, A.L. (1997) Antioxidant effect of flavonoids. Angiology 48, 39-44.

6. Cao, G., Sofic, E. \& Prior, R.L. (1997) Antioxidant and prooxidant behavior of flavonoids: Struc- 
ture-activity relationships. Free Radic. Biol. Med. 22, 749-760.

7. Cotelle, N., Bernier, J.L., Catteau, J.P., Pommery, J., Vallet, J.C. \& Gaydou, E.M. (1996) Antioxidant properties of hydroxy-flavones. Free Radic. Biol. Med. 20, 35-43.

8. Budzianowski, J., Skrzypczak, L. \& Wesołowska, M. (1990) Flavonoids and leiocarposide in four Solidago taxa. Sci. Pharma. 58, 15-23.

9. Metcalf, J.A., Gallin, J.I., Nausseef, W.M. \& Root, R.K. (1986) Preparation of soluble stimuli; in Laboratory Manual of Neutrophil Function; p. 23, Raven Press, New York.

10. Ferrante, H. \& Thong, Y.H. (1978) A rapid one-step procedure for purification of mononuclear and polymorphonuclear leukocytes from human blood using a modification of the Hypaque-Ficoll technique. J. Immunol. Methods 24, 389-393.

11. Gnojkowski, J., Baer-Dubowska, W., Klimek, D. \& Chmiel, J. (1984) Effect of toluidines on drug metabolising enzymes in rat liver, kidney and lung. Toxicology 32, 335-342.

12. Lowry, O.H., Rosebrough, N.J., Farr, A. \& Randall, R.J. (1951) Protein measurement with the Folin phenol reagent. J. Biol. Chem. 193, 265-275.

13. Cohen, H.J. \& Chovaniec, M.E. (1978) Superoxide generation by digitionin-stimulated guinea pig granulocytes. A basis for continuous assay for monitoring superoxide production and for study of the activation of the generating system. J. Clin. Invest. 61, 1081-1087.

14. Gelder, B.F. \& Slater, E.C. (1962) The extinction of cytochrome c. Biochim. Biophys. Acta 58, 593-595.

15. Weiss, S.J., Klein, R., Slivka, A. \& Wei, M. (1982) Chlorination of taurine by human neutrophils. Evidence for hypochlorous acid generation. J. Clin. Invest. 70, 598-607.

16. Bass, A.D., Parce, J.W., Dechatelet, L.R., Szeja, P., Seeds, M.C. \& Thomas, M. (1983) Flow cytometric studies of oxidative product formation by neutrophils: A graded response to membrane stimulation. J. Immunol. 130, 1910-1917.

17. Zielińska, M., Kostrzewa, A. \& Ignatowicz, E. (2000) Antioxidative activity of flavonoids in stimulated human neutrophils. Folia Histochem. Cytobiol. 1, 25-30.
18. Ohkawa, H., Ohishi, N. \& Yaga, K. (1979) Assay for lipid peroxides in animal tissues by thiobarbituric acid reaction. Anal. Biochem. 95, 351-358.

19. Havsteen, B. (1983) Flavonoids, a class of natural products of high pharmacological potency. Biochem. Pharmacol. 32, 1141-1148.

20. Sugihara, N., Arakawa, T., Ohnishi, M. \& Furuno, K. (1999) Anti- and pro-oxidative effects of flavonoids on metal-induced lipid hydroperoxidedependent lipid peroxidation in cultured hepatocytes loaded with alpha-linolenic acid. Free Radic. Biol. Med. 27, 1313-1323.

21. Tauber, A.I., Fay, J.R. \& Marletta, M.A. (1984) Flavonoid inhibition of the human neutrophil NADPH-oxidase. Biochem. Pharmacol. 33, 1367-1369.

22. Rice-Evans, C.A., Miller, N.J. \& Paganga, G. (1996) Structure-antioxidant activity relationships of flavonoids and phenolic acids. Free Radic. Biol. Med. 20, 933-956.

23. Walgren, R.A, Lin, J.T, Kinne, R.K.H. \& Walle, T. (2000) Cellular uptake of dietary flavonoid quercetin $4^{\prime}-\beta$-glucoside by sodium-dependent glucose transporter SGLT1. J. Pharmacol. Exp. Ther. 294, 837-843.

24. Walgren, R.A, Karnaky, K.J., Lindenmayer, G.E. \& Walle, T. (2000) Efflux of dietary flavonoid quercetin $4^{\prime}-\beta$-glucoside across human intestinal Caco-2 cell monolayers by apical multidrug resistance-associated protein-2. J. Pharmacol. Exp. Ther. 294, 830-836.

25. Robak, J. \& Gryglewski, R.J. (1996) Bioactivity of flavonoids. Pol. J. Pharmacol. 48, 554-564.

26. Robak, J. \& Gryglewski, R.J. (1988) Flavonoids are scavengers of superoxide anions. Biochem. Pharmacol. 37, 837-841.

27. Okamura, H., Mimura, A., Yakou, Y., Niwano, M. \& Takahara, Y. (1993) Anioxidant activity of tannins and flavonoids in Eucalyptus rostrata. Phytochemistry 33, 557-561.

28. Ignatowicz, E. \& Rybczyńska, M. (1994) Some biochemical and pharmacological aspects of free radical-mediated tissue damage. Pol. J. Pharmacol. 46, 103-114. 